\title{
Assessment of Healthy Working Lives initiative on workplace stress and eating behaviour (the NeuroFAST study)
}

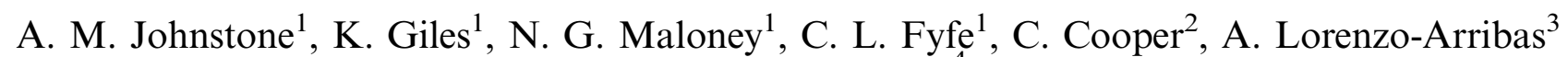 \\ and D. B. O'Connor ${ }^{4}$ \\ ${ }^{1}$ Rowett Institute of Nutrition and Health, University of Aberdeen, Greenburn Road, Aberdeen, AB21 9SB, ${ }^{2}$ Health \\ Science Building, University of Aberdeen, Foresterhill, Aberdeen, AB25 2ZD, ${ }^{3}$ Biomathematics and Statistics Scotland, \\ University of Aberdeen, Aberdeen, AB21 9SB and ${ }^{4}$ Institute of Psychological Sciences, University of Leeds, Leeds, \\ LS2 $9 J T$
}

The four major non-communicable diseases (cardiovascular disease, cancer, type 2 diabetes and chronic lung disease) account for over $60 \%$ of deaths in the world. ${ }^{(1)}$ Workplace health initiatives around the world are growing in number and scope, as employers come to realize that addressing employee health \& wellness is linked to increased productivity and reduced absenteeism, and that the returns on this strategic investment and overall health cost savings are high. We examined if a public health initiative called Healthy Working Lives (HWL), influenced outcomes in indices of stress and food intake and physical activity. We recruited public sector workers. Workplace 1 comprised staff from Aberdeen College and the University of Aberdeen, with both organisations holding the government initiative HWL; there were 150 subjects (41 male, 109 female) with a mean ( \pm SEM) age of $40 \cdot 8 \pm 0.9 \mathrm{yrs}$ (range 19-65yrs) and BMI of $24.8 \pm 0.3 \mathrm{~kg} / \mathrm{m}^{2}$ (range 15.9-39.1 kg/m ${ }^{2}$ ). Workplace 2 comprised secondary school staff in Aberdeen and Aberdeenshire, with no HWL initiative; there were 155 subjects (42 male, 113 female) with a mean ( \pm SEM) age of $44 \cdot 1 \pm 0.9 \mathrm{yrs}$ (range 22-68yrs) and BMI of $26.4 \pm 0.4 \mathrm{~kg} / \mathrm{m}^{2}$ (range $17 \cdot 3-60.0 \mathrm{~kg} / \mathrm{m}^{2}$ ). Subjects completed a concurrent record of $7 \mathrm{~d}$ weighed food intake, accelerometry and daily hassles scales. No significant differences in energy or nutrient intake were found between workplaces, (we examined total intake and snack intake). Similarly, there was no significant differences in physical activity between workplaces assessed by accelerometry as steps or activity levels. No significant differences for age, BMI, gender or workplace for total hours worked or total hours slept. We examined 5 types of stress or daily hassles (Stress Type 1: Ego-Threatening; Type 2: Interpersonal; Type 3: Work-Related; Type 4: Physical; Type 5: Environmental). Ironically, the staff working in the institutions with the HWL initiative report significantly higher stress. Subjects in Workplace 1 reported a higher number of total hassles per day than Workplace 2, mean ( \pm SEM). Total no of hassles were $8.39 \pm 0.44$ and $7.54 \pm 0.52$ for Workplace 1 and Workplace 2 , respectively $(\mathrm{p}=0.01)$. Similarly, subjects in Workplace 1 reported higher total hassles duration per week (hours) than Workplace 2. Mean ( \pm SEM) was $14.21 \pm 0.96$ and $11.89 \pm 0.95$ for Workplace 1 and Workplace 2, respectively $(p=0.02)$. The HWL initiative does not appear to influence energy intake, energy expenditure, energy balance or stress in the employees who participated in the NeuroFAST study. The HWL may have other potential health benefits (such as smoking cessation or mental health), but the effects on stress and nutritional profile are limited, indicated from the current dataset. If obesity and unhealthy behaviours are to be discouraged in the workplace, this requires evidence based intervention and robust evaluation.

The work is funded by the European Union Seventh Framework Programme (FP7/2007-2013) under grant agreement n 245009 for the 'NeuroFAST' grant.

1. WHO, Global Action Plan on the Prevention and Control of Non-communicable Diseases 2013-2020 (2013) http://apps.who.int/gb/ebwha/pdf_files/ WHA66/A66_R10-en.pdf. 